\title{
Synthesis and characterization of carbon nanotubes over iron carbide nanoparticles coated Al powder using thermal chemical vapor deposition
}

\author{
S. K. Singhal $\cdot$ R. K. Seth $\cdot$ Rashmi $\cdot$ \\ Satish Teotia $\cdot$ Mamta $\cdot$ Rajeev Chahal $\cdot$ \\ R. B. Mathur
}

Received: 17 November 2011/ Accepted: 6 February 2012/Published online: 22 February 2012

(c) The Author(s) 2012. This article is published with open access at Springerlink.com

\begin{abstract}
A simple method is described to synthesize carbon nanotubes (CNTs) by the thermal decomposition of toluene at $750^{\circ} \mathrm{C}$ over a thin catalyst film deposited on $\mathrm{Al}$ powder. This method allows the bulk metal surface to act as both the catalyst and support for CNT growth. The catalyst film on $\mathrm{Al}$ was prepared from an ethanol solution of iron nitrate. Under the growth conditions, iron nitrate formed an amorphous iron oxide layer that transform into crystalline $\mathrm{Fe}_{2} \mathrm{O}_{3}$, which was further reduced to $\mathrm{Fe}_{3} \mathrm{O}_{4}$ and $\mathrm{Fe}_{3} \mathrm{C}$. It is believed that the growth of CNTs took place on iron carbide nanoparticles that were formed from $\mathrm{FeO}$. The characterization of CNTs was mainly carried out by powder X-ray diffraction and scanning electron microscopy, $\mathrm{X}$-ray fluorescence and thermogravimatric analysis. The CNTs were found to be highly dispersed in Al powder. This composite powder could be further used for the fabrication of $\mathrm{Al}$ matrix composites using powder metallurgy process in which the powder were first cold pressed at 500-550 MPa followed by sintering at $620^{\circ} \mathrm{C}$ for $2 \mathrm{~h}$ under a vacuum of $10^{-2}$ torr. The mechanical properties of the sintered composites were measured using a microhardness tester and a Universal testing Instron machine.
\end{abstract}

S. K. Singhal $(\bowtie) \cdot$ R. K. Seth · Rashmi - R. B. Mathur

National Physical Laboratory, Council of Scientific

and Industrial Research, Dr. K.S. Krishnan Road,

New Delhi 110012, India

e-mail: sksinghal@mail.nplindia.ernet.in

S. Teotia $\cdot$ Mamta

Guru Jambeshwar University of Science and Technology,

Hisar, India

R. Chahal

Punjab University, Chandigarh, India
Keywords Carbon nanotubes - Thermal chemical vapor deposition $\cdot$ Metal-matrix composites

\section{Introduction}

Since the discovery of carbon nanotubes (CNTs) (Iijima 1991), these nanotubes have been used in a variety of applications because of its unique properties, e.g. low density ranging from 1.2 to $1.8 \mathrm{~g} / \mathrm{cc}$, high stiffness $(\sim 970$ $\mathrm{GPa}$ ), high thermal conductivity up to $3,000 \mathrm{~W} / \mathrm{mK}$, large aspect ratio $(1,000-10,000)$ and high specific strength of 55.5 GPa (Ajayan 1999; Kim et al. 2001; Treacy et al. 1996; Yu et al. 2000). The unique mechanical properties of carbon nanotubes make them promising reinforcements for synthesizing light-weight, high-strength composites for various applications. Although $\mathrm{Al}$ composites are mainly used in aerospace and automobile sectors to fabricate many components because of its lower density (a requirement necessary for the weight reduction for many components thereby saving fuels and hence energy), pure $\mathrm{Al}$ composites have not found to possess high mechanical strength, and, are, therefore, alloyed with a number of other metals to improve the mechanical properties. For the last one decade, many researches all over the world are trying to increase the mechanical properties of $\mathrm{Al}$ composites by reinforcing it with suitable binders, so that its strength could be improved significantly. In the recent years, several researchers are involved in the development of CNTs reinforced Al- matrix composites. The combination of unique properties of CNTs and $\mathrm{Al}$ has substantial potential in many weight sensitive applications although still considerable research is required to identify optimal processing route.

Till now, a few successful studies on CNTs reinforced Al matrix composites have been reported (Morsi et al. 
2010; Wang et al. 2009; Singhal et al. 2011; George et al. 2005; Bustamante et al. 2008; Laha et al. 2009; Zhou et al. 2007; He et al. 2007; Tokunaga et al. 2008; Lahiri et al. 2009), which are mainly attributed to the processing difficulties and lack of understanding of the strengthening mechanisms. Different methods, such as powder metallurgy (Morsi et al. 2010; Wang et al. 2009; Singhal et al. 2011; George et al. 2005; Bustamante et al. 2008), plasma spray forming (Laha et al. 2009), liquid infiltration (Zhou et al. 2007), molecular level mixing (He et al. 2007), high pressure torsion (Tokunaga et al. 2008) and roll bonding followed by annealing (Lahiri et al. 2009) etc. have been tried for the development of CNTs reinforced Al composites; of all these methods; however, PM route has been found to be very effective as using this route, composites of any shape and size could be easily fabricated. In this method, generally a mixture of Al powder and CNTs (taken in a predetermined weight ratio) is first cold pressed in a hardened steel die of any desired size and shape to make a green disc and then sintered either in an inert atmosphere $\left(\mathrm{N}_{2}\right.$, Ar, etc.) or under a vacuum of about $10^{-2}$ torr at temperatures below the melting temperature of $\mathrm{Al}\left(660^{\circ} \mathrm{C}\right)$. However, one of the major problems in this method is the homogeneous dispersion of CNTs in Al powder, because of the density difference between $\mathrm{Al}$ and CNTs and also the strong van der Waal's force of attraction between the walls of the tube. Because of this force of attraction between the CNTs, they tend to agglomerate rather than to disperse in Al matrix. In addition because of the large difference in the densities of $\mathrm{Al}(2.7 \mathrm{~g} / \mathrm{cc})$ and CNTs (1.4-1.8 g/cc) and also thermal mismatch it is very difficult to obtain a homogeneous mixture of $\mathrm{Al}$ powder and CNTs. Further, it is well known that the $\mathrm{Al}$ powders are hardly sinterable materials because of the oxide layers on its surface. This layer has to be broken up to achieve high packing density. Thus, the key factors for the fabrication of CNTs reinforced $\mathrm{Al}$ composites are (1) the homogeneous CNTs distribution and retention of its original structure, (2) sufficient adhesion at the matrix interface for effective load transfer. Therefore, for the past few years, efforts have been made to disperse CNTs in Al matrix using a number of process, including high energy ball milling (Esawi and Morsi 2007), molecular level mixing (He et al. 2007), nanoscale dispersion using natural rubber (Noguchi et al. 2004), acid functionalized CNTs (Deng et al. 2007), use of some surfactants, such as sodium dodecyl sulfate, etc. (Zhang and Gao 2007). Although a great success has been achieved using some of these methods, the dispersion of CNTs in Al powder is still not achieved up to a satisfactory level, and there is need to modify these methods or to discover some new methods for the better distribution of CNTs in Al matrix. Some of the results obtained on Al-CNTs composites, it has been found that the weight percentage of carbon nanotubes in $\mathrm{Al}$ matrix should be in the range $0.5-3.0 \mathrm{wt} \%$ to obtain composites having high micro hardness, tensile/compressive strength and other properties (Sridhar and Karthic 2009). Therefore, a controlled weight percentage of CNTs in $\mathrm{Al}$ powder is essential to obtain the optimal results. Although the molecular level mixing has been found to be very effective for the homogeneous dispersion of CNTs in $\mathrm{Cu}$ matrix, this method is not very effective for obtaining a homogeneous dispersion of CNTs in Al matrix (He et al. 2007). A homogeneous mixture consisting of CNTs (Ni)Al powders was prepared using a combination of CVD, calcinations and reduction in $\left[\mathrm{Ni}(\mathrm{OH})_{2} / \mathrm{Al}\right]$ (He et al. 2007). However, the composite fabricated from this composite powder was always contaminated with $\mathrm{Ni}$ nanoparticles. In the present method, we have grown CNTs directly on $\mathrm{Al}$ powder using thermal chemical vapor deposition (CVD) by the decomposition of toluene at $750^{\circ} \mathrm{C}$ in the presence of $\mathrm{Fe}_{3} \mathrm{C}$ thin catalyst-layer deposited over $\mathrm{Al}$ powder. The composite powder thus produced could be used for the fabrication of $\mathrm{Al}$ matrix composites.

\section{Experimental}

\section{Materials}

All chemicals of analytical grade were purchased from Fisher Scientific (India).

Preparation of a thin layer of iron nitrate on Al powders

To deposit a thin layer of iron nitrate on Al powders, the aluminum powder was first ball milled for $10 \mathrm{~h}$ at $200 \mathrm{rpm}$ using stainless steel balls of diameter $10 \mathrm{~mm}$. The balls to powder weight ratio was kept constant at 10:1. Also milling was carried out in the presence of Ar gas and $2 \mathrm{wt} \%$ stearic acid which prevented the oxidation and agglomeration of Al nanopowder. A small quantity of this powder was added to an ethanol solution of iron nitrate $(1 \mathrm{wt} \%)$ and the mixture was first sonicated for $4 \mathrm{~h}$ and then dried at $80^{\circ} \mathrm{C}$ using a magnetic stirrer. A thin layer of iron nitrate was found to deposit on the surface of Al powder.

Growth of carbon nanotubes on $\mathrm{Al}$ powders

A thermal CVD was used for the growth of CNTs on Al powder having a thin layer of iron nitrate. The details of CVD process has been described elsewhere (Mathur et al. 2008). A mixture of toluene and ferrocene was used as the precursor for the growth of CNTs, and Ar was used as the carrier gas. The growth of CNTs from the decomposition of this mixture was observed at $750^{\circ} \mathrm{C}$. However, as the melting temperature of $\mathrm{Al}$ is $660^{\circ} \mathrm{C}, \mathrm{Al}$ powder having a 
thin layer of iron nitrate was kept in a quart boat at the end of the reactor where the temperature was calibrated to $600^{\circ} \mathrm{C}$. The deposition time was varied from 0.5 to $1.5 \mathrm{~h}$.

\section{Fabrication of Al-CNTs composites}

To fabricate the composites, the CVD-coated Al powder was further blended with a predetermined weight percentage of pure and milled $\mathrm{Al}$ powder at $350 \mathrm{rpm}$ for $2 \mathrm{~h}$ in the presence of $\mathrm{Ar}$ gas. The weight percentage of $\mathrm{Al}$ was adjusted so that in the final mixture the CNTs is $1.5 \mathrm{wt} \%$ of the total weight of the sample. A homogeneous mixture of $\mathrm{Al}$ and $1.5 \mathrm{wt} \% \mathrm{CNTs}$ were pressed in the form of a circular disc (diameter $6.0 \mathrm{~mm}$ ) and a rectangular shaped (length $45 \mathrm{~mm}$, width $8 \mathrm{~mm}$ ). The circular shaped samples were mainly used for microhardness, compressive strength measurements (as per ASTM standards) and other characterizations, such as formation of phases formed during the sintering conditions and morphology of the composites were carried out on rectangular shaped samples. All samples were first cold pressed at a constant pressure of $550 \mathrm{MPa}$ and then sintered at $620^{\circ} \mathrm{C}$ for $2 \mathrm{~h}$ under a vacuum of $10^{-2}$ torr. The heating and cooling rates were adjusted to 20 and $10^{\circ} \mathrm{C} / \mathrm{min}$, respectively. For comparison, composites under similar processing conditions were also fabricated using pure $\mathrm{Al}$ powder. All sintered composites were polished using a fine diamond paste and various mechanical and other characterizations were made.

\section{Instrumentation}

A scanning electron microscope (SEM, model LEO 440) equipped with an energy-dispersive spectrometer (EDS, model Oxford Link ISIS 300) was used to study the growth and morphology of CNTs on Al powder. Microstructural characterization at high magnifications of the CNTs produced by CVD were carried out using a transmission electron microscopy (TEM, model JEOL JEM 200 CX), operated at the electron accelerating voltage of $200 \mathrm{kV}$. A FEI model Techani $\mathrm{G}^{2}$ F30 STWIN, $300 \mathrm{kV}$ machine was used to carry out high-resolution transmission electron microscopy (HRTEM). Growth of CNTs on Al powder was also estimated by thermogravimetric analysis (TGA) using TGA DSC 1/1600/LF, Mettler Toledo, Switzerland. For this purpose, a known weight of CNTs grown $\mathrm{Al}$ powder was heated in air very slowly $\left(10^{\circ} \mathrm{C} / \mathrm{min}\right)$ up to a temperature of $600^{\circ} \mathrm{C}$ (below the melting temperature of $\mathrm{Al}$ ) and the weight loss was determined. The flow rate of air was kept constant at $100 \mathrm{ml} / \mathrm{min}$. Almost all the CNTs are oxidized at $\sim 450^{\circ} \mathrm{C}$ and the loss in weight of the sample correspond to the amount of CNTs grown on $\mathrm{Al}$ powder using CVD. Quantitative elemental analysis of the sample was also carried out using Rigaku ZSX Primus Wavelength Dispersive X-ray Fluorescence Spectrometer (WD-XRF). The spectrometer has a Rh-target, end-window, $4 \mathrm{~kW}$, sealed X-ray tube as the excitation source and scintillation (SC) for heavy elements and flow proportional counter (F-PC) for light elements as the detectors. Specimen for the XRF measurements was in the form of a pellet prepared from the powder sample at a pressure of about $500 \mathrm{MPa}$. Measurements were made at a temperature of $36.5^{\circ} \mathrm{C}$ under vacuum. The $\mathrm{K} \alpha \mathrm{X}$-spectral lines were recorded at a tube rating of $30 \mathrm{kV}$ and $100 \mathrm{~mA}$, using F-PC and analyzer crystals RX61 (C K $\alpha)$, RX35 (O K $\alpha)$ and PET (Al K $\alpha$ ). The X-ray diffraction (XRD) analysis of the composites fabricated in the present work was carried out by means of Rigaku D/MAX-2400 X-ray diffraction analysis (Rigaku Corp. Tokyo, Japan) using $\mathrm{CuK} \alpha$ radiation $(\lambda=0.15418 \mathrm{~nm})$ at room temperature. Microhardness measurements on the composites was carried out on a Zwick 3212 (Germany) hardness tester under a load of $100 \mathrm{~g}$ for $15 \mathrm{~s}$ dwell time and a universal testing Instron machine (Model 4041) was used to study the various mechanical properties.

\section{Results and discussion}

Figure $1 \mathrm{a}$ and $\mathrm{b}$ shows a typical transmission electron microscopy (TEM) images of CNTs grown on $\mathrm{Al}$ powder from a mixture of toluene and ferrocene at $750^{\circ} \mathrm{C}$ using CVD (Mathur et al. 2008). The diameter of the synthesized CNTs was 50-100 nm and length several microns. Most of the CNTs are of uniform size and cylindrical morphology. Figure 1c and d shows an SEM image of Al powder containing CNTs deposited on its surface at $600^{\circ} \mathrm{C}$ for a duration of $1.5 \mathrm{~h}$ using the above-mentioned CVD process. Figure 1d is the SEM image at high magnification. The CNTs were found to disperse well in Al powder. From the EDS analysis (Fig. 2), it was observed that the concentration of CNTs grown on $\mathrm{Al}$ powder was $\sim 6 \mathrm{wt} \%$. Figure $3 \mathrm{a}$ shows another SEM micrograph of Al powder coated with CNTs at $600^{\circ} \mathrm{C}$ for a duration of $1.5 \mathrm{~h}$. CNTs grown on $\mathrm{Al}$ powder are clearly seen as shown in the encircles. The EDS analysis (Fig. 3b) of this composite powder showed $\sim 7 \mathrm{wt} \%$ of $\mathrm{C}$ corresponding to CNTs. However, as the EDS has been done on a very small localized region the quantitative estimation of carbon. To obtain more reliable quantitative data on the growth of CNTs on Al powder thermogravimetric (TGA) and X-ray fluorescence (XRF) analysis were carried out. Figure $3 \mathrm{c}$ shows a TGA spectrum of the same sample of CNTs coated Al powder at $600^{\circ} \mathrm{C}$ for a duration of $1.5 \mathrm{~h}$. The mixture of CNTs-coated Al powder was heated in air up to a temperature of $600^{\circ} \mathrm{C}$ 

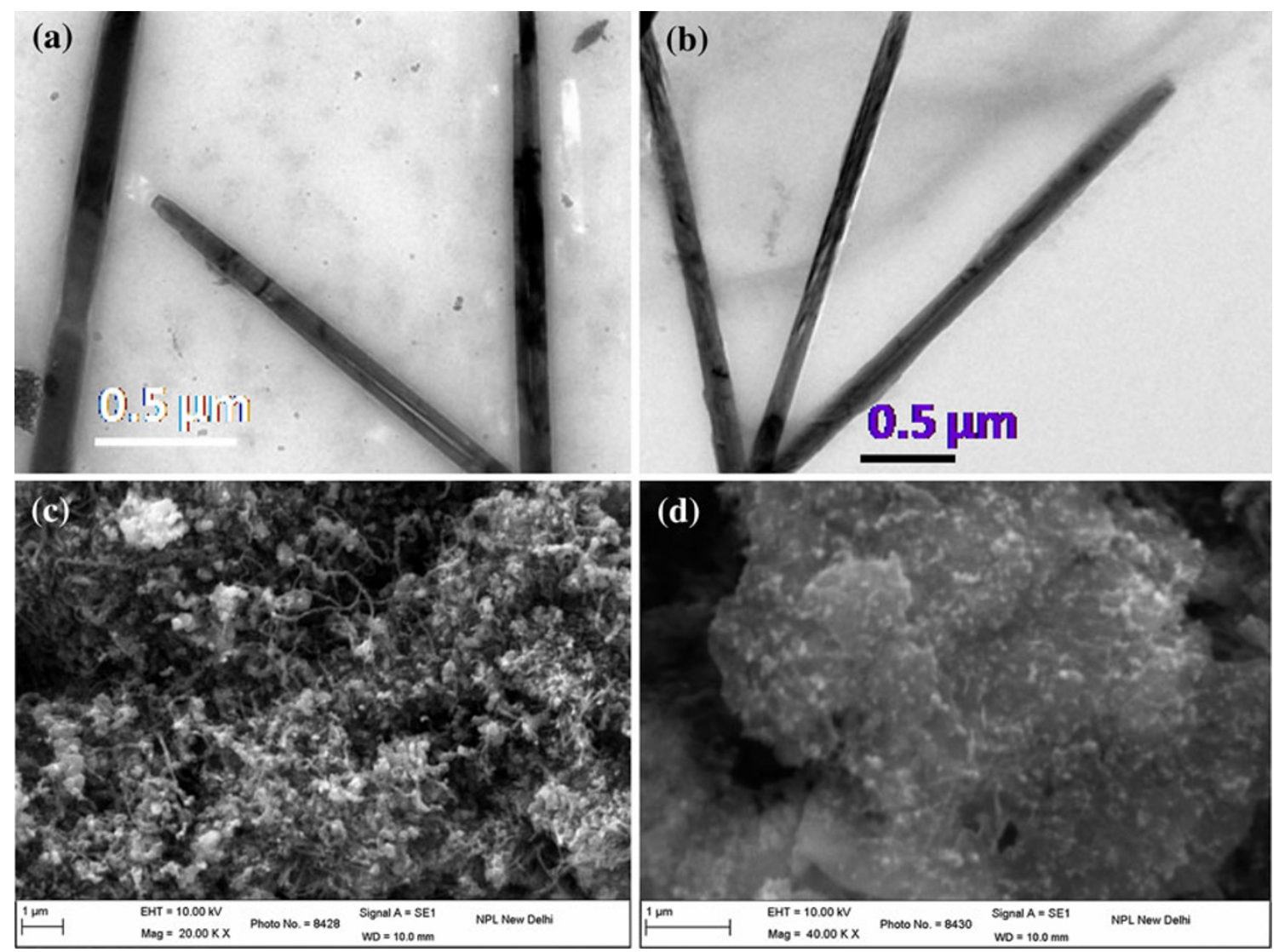

Fig. 1 a, b TEM image of CNTs grown on Al powder by CVD. SEM micrographs of CNTs grown on Al powder from a mixture of toluene and $8 \mathrm{wt} \%$ ferrocene. c At low and $\mathbf{d}$ at high magnification (deposition time $1 \mathrm{~h}$ )

Fig. 2 EDS spectra of CNTs grown on $\mathrm{Al}$ powder by $\mathrm{CVD}$

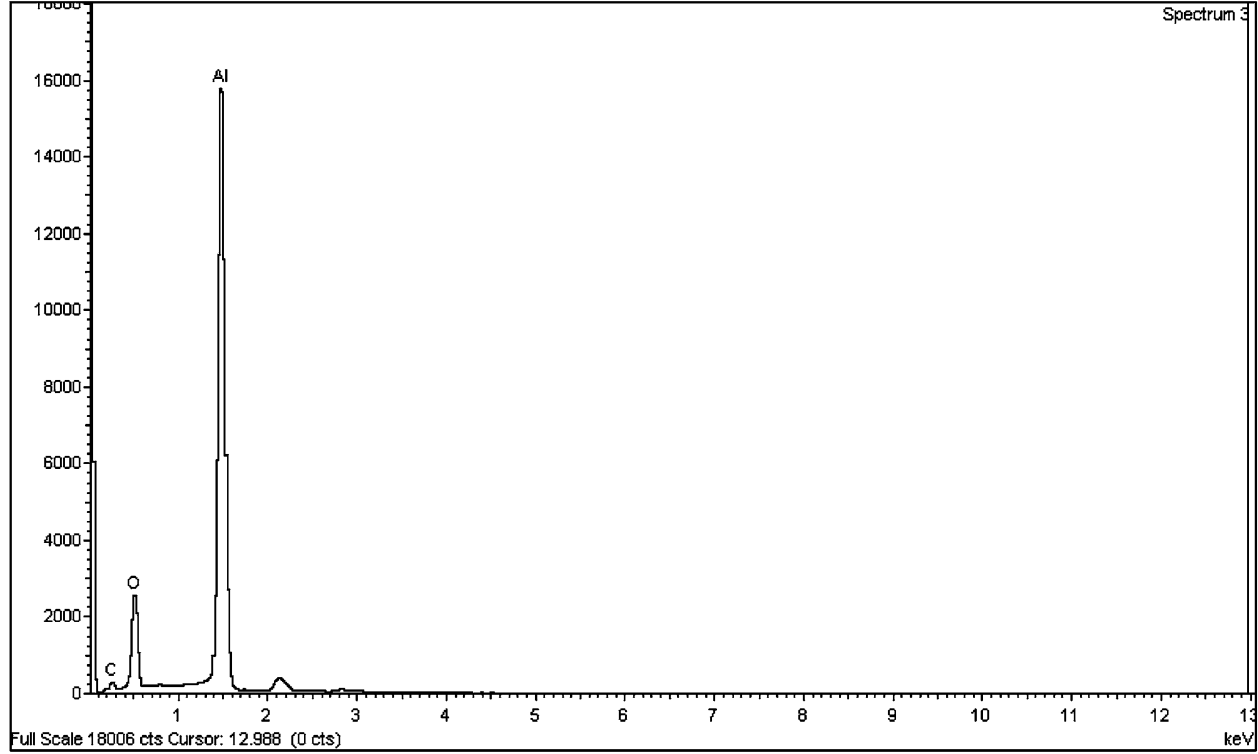

(below the melting temperature of $\mathrm{Al}$ ) and the weight loss was estimated. Almost all the CNTs present in Al/CNTs mixture were found to oxidize at a temperature of about $485^{\circ} \mathrm{C}$. From the weight loss, it was estimated that the weight percentage of CNTs grown on $\mathrm{Al}$ powder was $4.25 \%$. 

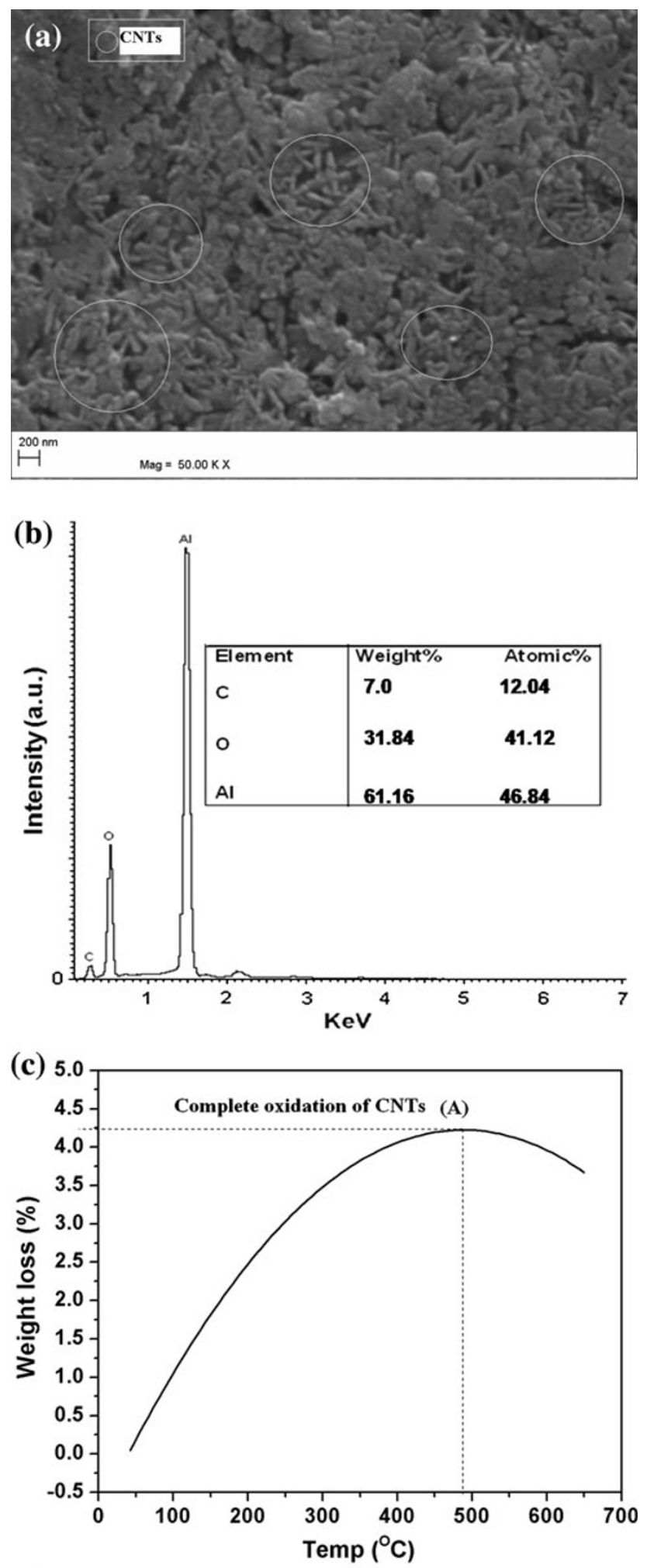

Fig. 3 a SEM micrograph of CNTs grown on Al powder after $1.5 \mathrm{~h}$ deposition using CVD. b EDS spectrum of CNTs coated Al powder $(1.5 \mathrm{~h}$ deposition time). The inset shows the wt $\%$ of different constituents of the composite powder. c TGA of Al/CNTs composite powder
Figure $4 \mathrm{a}-\mathrm{c}$ shows the XRF spectra of the same sample of CNTs coated Al powder used for TGA analysis. The peaks at $2 \theta \sim$ (a) $32.5^{\circ}$ (b) $50.8^{\circ}$ and (c) $144.7^{\circ}$ correspond to $\mathrm{C} \mathrm{K} \alpha, \mathrm{O} \mathrm{K} \alpha$ and $\mathrm{Al} \mathrm{K} \alpha$ spectral lines respectively, thus confirming the presence of $\mathrm{C}, \mathrm{O}$ and $\mathrm{Al}$ elements in the composite powder. From this figure, it is seen that the weight percentage of C (corresponding to CNTs) was $3.95 \%$, which was almost equivalent to that observed in TGA analysis shown in Fig. 3a. However, these mixtures of $\mathrm{Al}$ and CNTs could not be found suitable for the fabrication of Al matrix composites using powder metallurgy process as the optimum concentration of CNTs in $\mathrm{Al}$ powder were found to be $0.5-2 \mathrm{wt} \%$ for the optimum results (Sridhar and Karthic 2009). Hence, a detailed and systematic study was made further to deposit only a small concentration of CNTs on Al powder using thermal CVD by varying different process parameters, such as weight percentage of ferrocene in toluene, reaction temperature, duration of reaction, flow of carrier gases, weight percentage of iron nitrate in $\mathrm{Al}$ powder and so on, so that it could be used further for the fabrication of Al-CNTs composites with optimum properties. To increase the dispersion of CNTs in Al powder, the mixture was further blended with pure and milled $\mathrm{Al}$ powder at $350 \mathrm{rpm}$ for $2 \mathrm{~h}$ in the presence of stearic acid (used as a process control agent). Milling in the presence of a process control agent enables a balance between fracture and welding to be established, enabling refinement of the powder particle size. Further, in addition to prevent the excessive welding of $\mathrm{Al}$ powders, it also reacted with $\mathrm{Al}$ leading to the formation of second phases, such as $\gamma-\mathrm{Al}_{2} \mathrm{O}_{3}$ (JCPDS: $10-0425$ 1999) and/or $\mathrm{Al}_{4} \mathrm{C}_{3}$ (JCPDS: 34-0799 1999).

It must be mentioned that during the high energy ball milling of $\mathrm{Al} / \mathrm{CNT}$ sowder with pure $\mathrm{Al}$, a desired concentration of CNTs in Al powder could be obtained. Figure 5a and b shows SEM micrographs of CNTs coated on Al powder after $1.5 \mathrm{~h}$ deposition time from a mixture of toluene and $8 \%$ ferrocene at $600^{\circ} \mathrm{C}$ followed by blending for $2 \mathrm{~h}$ in the presence of $2 \mathrm{wt} \%$ stearic acid. The CNTs were found to be highly dispersed on the entire surface of Al powder.

Figure 6 shows a typical XRD pattern of Al-CNTs composite powder using CVD followed by blending for $4 \mathrm{~h}$. The XRD peaks of CNT (002) and (004) planes at $2 \theta=26$ and $44^{\circ}$ could be clearly seen in this pattern along with $\mathrm{Al}, \mathrm{Fe}_{3} \mathrm{C}$ and $\mathrm{Fe}_{3} \mathrm{O}_{4}$. From the various phases formed, we can deduce that under the growth conditions iron nitrate thin layer coated on $\mathrm{Al}$ powder is slowly decomposed to $\mathrm{Fe}_{2} \mathrm{O}_{3}$ in the presence of excess of nitrogen. $\mathrm{Fe}_{2} \mathrm{O}_{3}$ crystals are reduced to some intermediate oxides $\left(\mathrm{Fe}_{3} \mathrm{O}_{4}, \mathrm{FeO}\right.$, etc.) by the hydrogen released from the pyrolysis of toluene. 

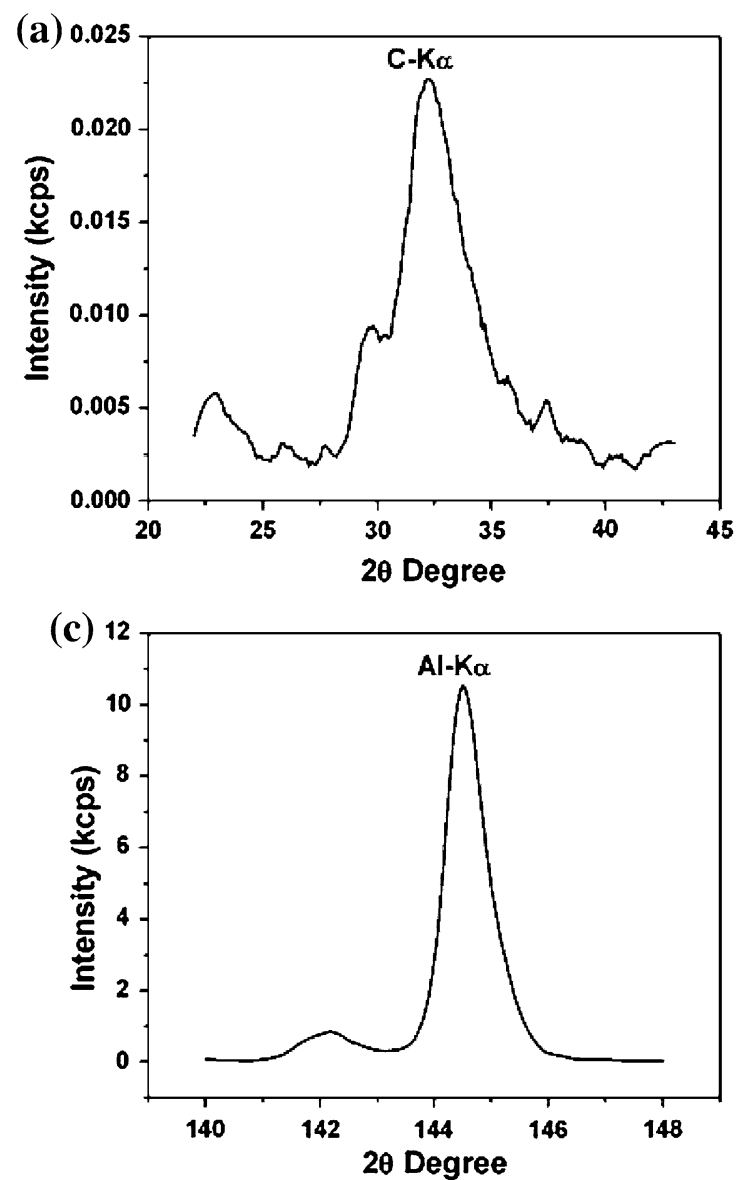

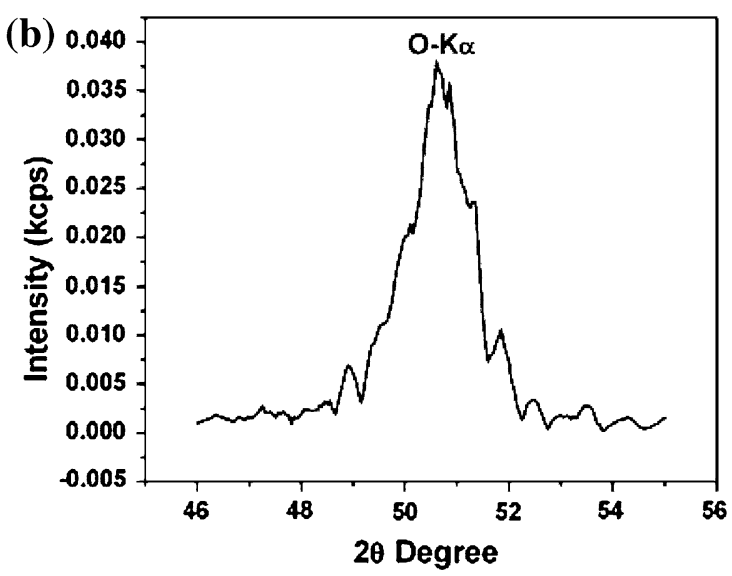

(d)

\section{Element Weight \%}

C

3.95

$\mathbf{o}$

$\mathbf{3 0 . 8 0}$

Al

Fig. 4 XRF spectrum of CNTs coated on Al powder using thermal CVD

$\mathrm{FeO}$ is finally transformed into metastable $\mathrm{Fe}_{3} \mathrm{C}$. Formation of $\mathrm{Fe}_{3} \mathrm{C}$ provides active nucleation sites for the growth of CNTs on $\mathrm{Al}$ powder, and as the concentration of iron nitrate increases, the formation of such potential nucleation sites also increases. Thus, a high density of CNTs on Al powder was observed using the present method. It must be mentioned that the growth of CNTs was also observed on stainless steel (Baddour et al. 2008). In this experiment, CNTs were grown on stainless steel powder by passing $\mathrm{C}_{2} \mathrm{H}_{2}$ gas over steel powder (taken in a quartz boat) kept in a quartz furnace at a temperature of about $750-800^{\circ} \mathrm{C}$. Nanoparticles (Fe) from stainless steel powder acts as a catalyst and the deposition of CNTs was observed on the entire surface of steel powder. Stainless steel seems to be an effective candidate for CNTs growth due to its high iron content $(\sim 66 \%)$ and the possibility to tailor active sites for the growth process. However, in this experiment, no systematic study has been made to control the growth of CNTs on steel powder, and thus, no data are available on the concentration of CNTs deposited or grown on stainless steel powder.

In the present method, we tried to grow CNTs directly on $\mathrm{Al}$ powder by placing it in a quartz boat kept at a temperature of about $600^{\circ} \mathrm{C}$ (below the melting temperature of $\mathrm{Al} \sim 650^{\circ} \mathrm{C}$ ) near the end of the reactor. A mixture of toluene and ferrocene was fed from one of the quartz reactor into the central zone where the temperature was around $750^{\circ} \mathrm{C}$. Ar was used as the carrier gas. This temperature was found to be necessary for the growth of CNTs. However, our initial experiments did not show any growth of CNTs on the surface of pure Al powder. Therefore, we modified the process and used a mixture of $\mathrm{Al}$ powder containing $1.0 \mathrm{wt} \%$ iron nitrate $\left(\mathrm{Fe}\left(\mathrm{NO}_{3}\right)_{3} \cdot 9 \mathrm{H}_{2} \mathrm{O}\right)$ instead of pure $\mathrm{Al}$ powder. From our earlier work, it is reported that a high growth of CNTs can be obtained from the decomposition of toluene at $750^{\circ} \mathrm{C}$ in the presence of ferrocene, used as a catalyst (Mathur et al. 2008). Using this mixture, a very high growth rate of CNTs was observed on Al powder containing about $1 \mathrm{wt} \%$ iron nitrate at $600^{\circ} \mathrm{C}$.

To use this composite powder useful for the fabrication of composites, it was blended at $350 \mathrm{rpm}$ with pure and milled $\mathrm{Al}$ powder for another $2 \mathrm{~h}$ in the presence of stearic acid keeping the ball to powder weight ratio of 10:1. The weight percentage of $\mathrm{Al}$ was estimated so that in the final mixture the percentage of CNTs is $\sim 1.5 \mathrm{wt} \%$ as already optimized by earlier researchers (Sridhar and Karthic 

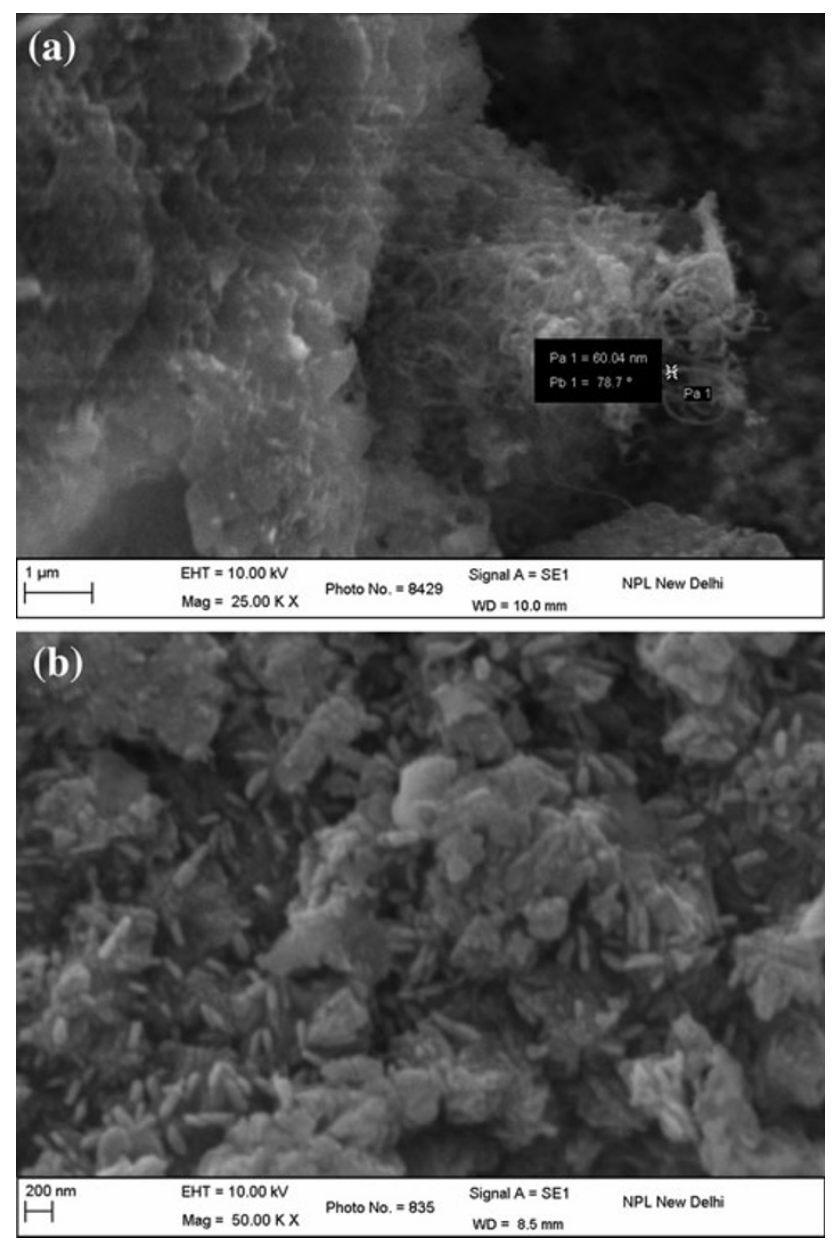

Fig. 5 SEM micrographs showing high density of CNTs grown on Al powder (deposition time $=1.5 \mathrm{~h}$ ). a At low and $\mathbf{b}$ at high magnification

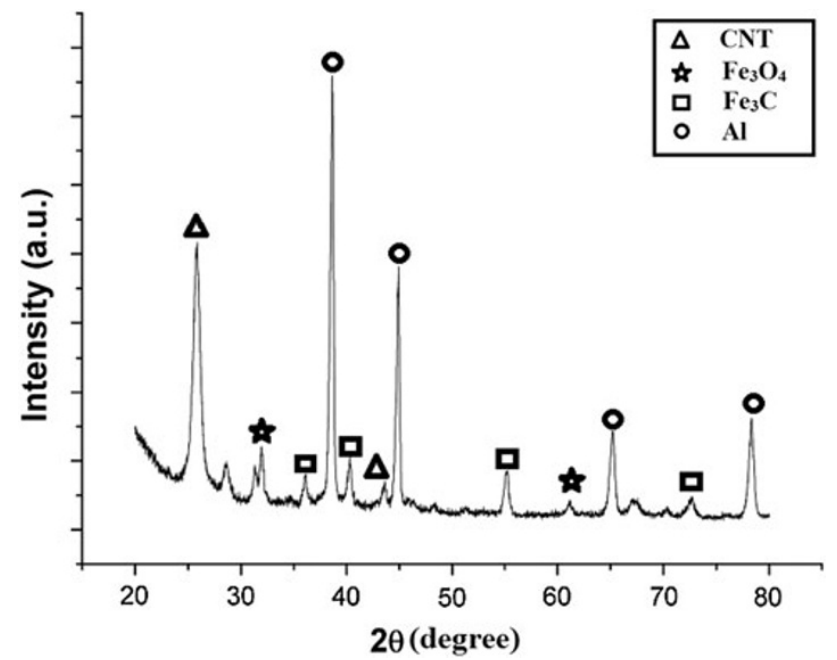

Fig. 6 XRD pattern of Al-CNT composite powder synthesized using thermal CVD
2009). The blended mixture was cold pressed at $550 \mathrm{MPa}$ followed by sintering at $620^{\circ} \mathrm{C}$ for $2 \mathrm{~h}$ under a vacuum of $10^{-2}$ torr. The samples were fabricated in accordance to ASTM standards, so that various mechanical tests could be made. Before characterization, the sintered composites were polished well using a fine diamond paste. The microhardness tests were carried out in accordance with ASTM Standard E-384. Samples for measuring compressive strength were prepared as recommended by ASTM Standard E9. Three point bending strength were prepared as per ASTM standard E 399-90S. At least 10 sets of results were obtained for each test to confirm the repeatability of the results. The average microhardness of some of the composites fabricated in the present work was about $200 \pm 10 \mathrm{~kg} / \mathrm{mm}^{2}$, which is much higher than the hardness values reported earlier. Similarly other mechanical properties, such as compressive strength of the composites using the composite powder synthesized in the present method was also found to be $280 \pm 10 \mathrm{MPa}$ which is much higher to those obtained using pure $\mathrm{Al}$ powder (100 MPa). Hence, it can be concluded that the present method could be used for the fabrication of Al matrix composites with improved mechanical properties. The mechanical properties of $\mathrm{Al}$ composites increases with the addition of CNTs because of the load sharing between $\mathrm{Al}$ matrix and CNTs. CNTs can withstand much higher loads than Al matrix and hence there is a substantial increase in the mechanical properties of the composites. Homogeneous dispersion of CNTs in Al matrix is the key factor in the fabrication of composites. If CNTs agglomerate at one site then that area will receive the maximum load and hence formation of cracks will be seen at that point, and also the rest of the composite will not be able to withstand heavy loads due to lack of load transfer to CNTs and the whole structure will collapse. It is, therefore, extremely important to have a highly dispersed system so that the load sharing is done in an even manner minimizing the load in a single area, dispersing the load evenly and hence increasing the total load that a composite can withstand. The present method is believed to provide a highly dispersed system, where we can achieve a homogeneous dispersion of CNTs in Al matrix using thermal CVD combined with high energy ball milling and thus can be used for the fabrication of composites with improved mechanical properties.

Acknowledgments The authors are grateful to the Director, National Physical Laboratory, New Delhi, for his permission to publish the results reported in this paper. Sincere thanks are due to Mr. K.N. Sood and Mr. Jai for their help in SEM and EDS characterization of CNTs coated on Al powder.

Open Access This article is distributed under the terms of the Creative Commons Attribution License which permits any use, distribution, and reproduction in any medium, provided the original author(s) and the source are credited. 


\section{References}

Ajayan PM (1999) Nanotubes from carbon. Chem Rev 99:1787-1800 Baddour CE, Fadlallah F, Nasuhoglu D, Mitra R, Vandsburger L, Meunier JL (2008) A simple thermal CVD method for carbon nanotubes. Carbon 47:313-347

Bustamante RP, Guel IE, Flores WA, Yoshida MM, Ferreira PJ, Sanchez RM (2008) Novel Al-matrix nanocomposites reinforced with multi-walled carbon nanotubes. J Alloy Compd 450:323-326

Deng CF, Wang DZ, Zhang XX, Li AB (2007) Processing and properties of carbon nanotubes reinforced aluminium composites. Mater Sci Eng A 444(1-2):138-145

Esawi A, Morsi K (2007) Dispersion of carbon nanotubes (CNTs) in aluminum powder. Compos Pt A Appl Sci Manuf 38(2):646-650

George R, Kashyap KT, Rahul R, Yamdagni S (2005) Strengthening in carbon anotubes/aluminium (CNT/Al) composites. Script Mater 53:1159-1163

He CN, Zhao NQ, Shi CS, Du X, Li J, Li H, Cui Q (2007) An approach to obtaining homogeneously dispersed carbon nanotubes in $\mathrm{Al}$ powders for preparing reinforced Al-matrix composites. Adv Mater 19:1128-1132

Iijima S (1991) Helical microtubules of graphitic carbon. Nature 354:56-58

Joint Committee of Powder Diffraction Standards (JCPDS: 10-0425) (1999) International Centre for Diffraction Data

Joint Committee of Powder Diffraction Standards (JCPDS: 34-0799) (1999) International Centre for Diffraction Data

Kim P, Shi L, Majumdar A, McEuen PI (2001) Thermal transport measurements of individual multiwalled nanotubes. Phys Rev Lett 87:215502-215505

Laha T, Chen Y, Lahiri D, Agrawal A (2009) Tensile properties of carbon anotubes reinforced aluminum nanocomposite fabricated by plasma spray forming. Compos Part A 40:589-594

Lahiri D, Bakshi SR, Keshri AK, Liu Y, Agrawal A (2009) Dual strengthening mechanisms induced by carbon nanotubes in roll bonded aluminum composites. Mater Sci Eng A 523(1-2):263270

Mathur RB, Chatterjee S, Singh BP (2008) Growth of carbon nanotubes on carbon fiber substrates to produce hybrid/phenolic composites with improved mechanical properties. Compos Sci Technol 68:1608-1615

Morsi K, Esawi AMK, Lanka S, Sayed A, Taher M (2010) Spark plasma extrusion (SPE) of ball-milled aluminium and carbon nanotubes reinforced aluminium composite powders. Compos $\mathrm{Pt}$ A Appl Sci Manuf 41:322-326

Noguchi T, Magario A, Fukagawa S, Shimizu S, Beppu J, Seki M (2004) Carbon nanotubes/aluminium composites with uniform dispersion. Mater Trans 45:602-604

Perez-Bustamante R, Estrada-Guel I, Antunez-Flores W, MikiYoshida M, Ferreira PJ, Martinez-Sanchez R (2008) Novel Al-matrix nanocomposites reinforced with multi-walled carbon nanotubes. J Alloys Compd 450:323-326

Singhal SK, Pasricha R, Teotia S, Girish K, Mathur RB (2011) Fabrication and characterization of Al-matrix composites reinforced with amino-functionalized carbon nanotubes. Compos Sci Technol 72:103-111

Sridhar I, Karthic RN (2009) Processing and characterization of MWCNT reinforced aluminum matrix composites. J Mater Sci 44:1750-1756

Tokunaga T, Kaneko K, Horita Z (2008) Production of aluminiummatrix carbon anotubes composite using high pressure torsion. Mater Sci Eng A 490:300-304

Treacy MMJ, Ebbesen TW, Gibson JM (1996) Exceptionally high Young's modulus observed for individual carbon nanotubes. Nature 381:678-680

Wang L, Choi H, Myoung JM, Lee W (2009) Mechanical alloying of multi-walled carbon nanotubes and aluminium powders for the preparation of carbon/metal composites. Carbon 47:3427-3433

Yu MF, Lourie O, Dyer MJ, Moloni K, Kelly TF, Ruoff RS (2000) Strength and breaking mechanism of multiwalled carbon nanotubes under tensile load. Science 287:637-640

Zhang J, Gao I (2007) Dispersion of multiwalled carbon nanotubes by sodium dodecyl sulfate for preparation of modified electrodes toward detecting hydrogen peroxide. Mater Lett 61:3571-3574

Zhou SM, Zhang XB, Din Z, Min C, Xu G, Zhu W (2007) Fabrication and tribological properties of carbon nanotubes reinforced $\mathrm{Al}$ composites prepared by pressure-less infiltration technique. Compos Part A Appl Sci Manuf 38:301-306 